\title{
Bidding Approach in Deregulated Power Market: A Review
}

\author{
Manisha Saini, Ajay Bhardwaj \\ Department of Electrical Engineering, Swami Keshvanand Institute of Technology, Management \& Gramothan, Jaipur- \\ 302017 (INDIA) \\ Email: msmanisha.saini94@gmail.com, ajay.bhardwaj@skit.ac.in \\ Received 31.08.2021, received in revised form 14.09.2021, accepted 14.09.2021 \\ doi: 10.47904/IJSKIT.11.2.2021.5-10
}

\begin{abstract}
This paper is based on bidding techniques in the deregulated power souk. Various countries throughout the world modified their power economics to make the regulated power system to deregulated power system (competition based) to foster opposition and improve efficiency. Bidding price reduction and stabilization are provided by competition. The profit maximization of power utilities is inextricably linked to bidding methods. Based on state-of-the-art research, authors studied bidding approach and modelling methodologies to the various souk types. It also examines the competitive souk model of the global energy souk. The literature review highlights the fact that most study is focused on the supply side of the souk, while the demand side is still mostly unexplored. To maximise their personal profit in deregulated power souk, suppliers and buyers have an appropriate bid technique. This sparked a massive research effort by academics and practitioners in the worlds deregulated power souks. As a result, several authors have proposed numerous strategies to tackle the bid problem in the power souk. The purpose of this work is to lay out the best bid approach for generation companies and end users in the power souk. A literature review based on bid approaches used in power souk is also included in this study.
\end{abstract}

Keywords- Power souk, Bidding Strategy, Market Clearing Price (MCP), Optimization Problem and Profit Maximization.

\section{INTRODUCTION}

Deregulation of the electricity system ushered in a rebellion that forever altered the appearance of the Electricity souk. The entry of new competitors into the souk resulted in a significant improvement in the reliability of the system. Consumers had the option to prefer their own operators; something will not do in a controlled souk, thanks to the competition that was brought about by deregulation. As a result of the souk's incorporation of participants, they were able to use creative approaches to get them more costeffective and consistent, with the goal of increasing profits. Several bodies, such as the independent system operator (ISO) and the power exchange, were created to ensure the efficient working of the power souk.

Bid is an efficient technique to reduce souk derelictions by providing equal opportunity to all participants, hence limiting souk power. Bidding takes place in either the day-ahead or real-time souks. The participants must devise a bidding strategy that provides the highest possible profit. The researchers' major goal is to design effective bidding techniques and a countermeasure for all uncertainty. Diverse studies dealing with various objectives with the goal of profit maximization were conducted to discover the best strategic bidding approaches. Various limitations were evaluated as part of an approach for developing an optimal bidding strategy for profit maximization. During this bilateral transaction procedure, the DER aggregator earns money. Several methodologies for optimal bidding strategies have been described in the literature, along with the types of uncertainties they face and how to solve them. Around the world, the electricity industry saw significant reforms, and opposition in the power souk grew dramatically, moving from regulated power utilities to deregulated souk power.

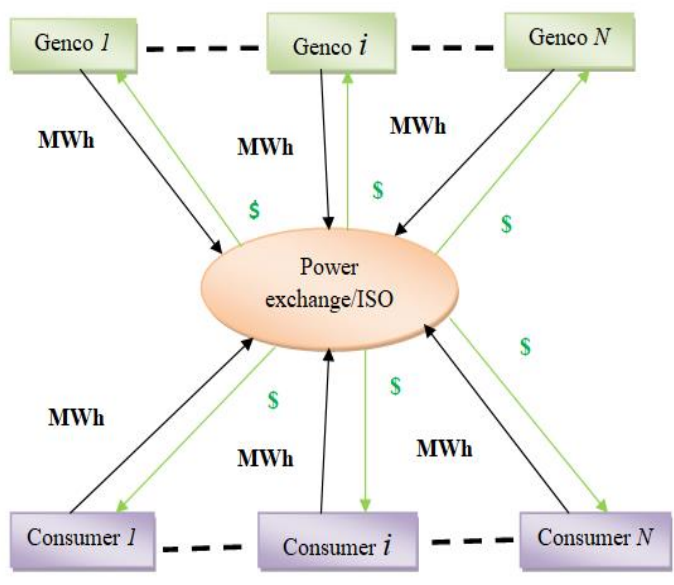

Fig. 1 Sonak Structure

The loosening of the power souk, open network access, and deregulated energy souks, among other things, began in the 1980s in the United Kingdom and a few other nations [1]. The economic success of the country is aided by the efficient working and administration of power system. The objective of energy reform is to transform monopolies into oligopolies, increase accessibility of fuel, design power production and information technologies, and improve service quality while decreasing prices [2]. Several countries across the world have implemented souk reform initiatives such as energy souk liberalization, privatization, and/or restructuring since the mid-1980s.In 1987, Chile became the first country to launch a thorough souk reform program. 
The government of India began reforming the electric power business in 2003, when it approved the Electricity Act and other laws, including the NEP and TP. Since 2008, two power exchanges in India are (PXIL) and (IEX) [3]. The three techniques for developing bidding models include evaluating the $\mathrm{MCP}$, game concept, and competitor behavior.

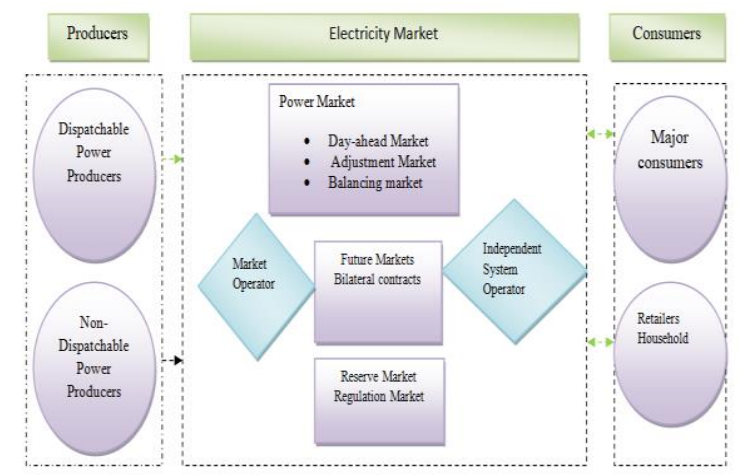

Fig. 2 Structure of deregulated electricity souks

Traders must bid at or near the marginal price in a competitive souk to maximize profit. The energy souk, however, is not completely competitive in terms of price takers. Consequently, electricity firms set their prices somewhat higher than their marginal cost of production. A price taker uses strategic bargaining to take advantage of a defective souk by bidding more than the marginal cost [5]. Fig 2 depicts the structure of a deregulated energy market.

The Indian power industry has seen significant changes in recent years. The development of competitive bid, the expansion of two-sided commerce, and the implementation of power trade are all contributing to this. The focus of the power souk reorganization is to remove monopolies in both generation and trading. Consequently, whenever possible, competition should be implemented at all levels. The sudden changes, however, have raised worries about the electrical souk's oligopolistic character, strategic bidding by suppliers, souk power abuse, price demand elasticity, and other issues. There used to be a traditional monopoly structure in the electricity industry before deregulation. Following deregulation, big consumers (buyers) and generators (suppliers) begin to participate in power transactions with the assistance of an independent system operator to guarantee system security (ISO).

The competitive electricity souk pits many producing, transmission, and distribution firms against each other, as well as the ISO. In contrast to ideal souk competition, the developing electrical souk structure resembles an oligopoly. All of these variables combine to make it possible for just a few producing firms to serve a particular geographic area, and each provider may optimize profit in this environment by strategic bidding. Suppliers must bid at marginal cost to maximize profit in a fully competitive souk. Due to the oligopolistic character of energy souks, the problem for suppliers is to provide the most optimum offer based on their own costs, technological limitations, and competition and souk behavior expectations. An optimal solution of problem is called bidding approach.

Depending on the objective functions, restrictions will not be accessible, making conventional approaches ineffective. One of the basic flaws of heuristic methods like GA, SA, EP, and PSO is their sensitivity to parameter choices such as evolution programming operator probability in GA, EP, and so on.

\subsection{Souk Structure}

In the electrical industry, energy buyers and producers propose bids to the ISO and ISO prepare the amount of energy to be traded. Rather of competing for individual consumers, merchants in a energy souk fight to provide power to the utility. If a souk member bid excessively high, the item is unable to trade. On another side, purchasers fight for purchasing power and may be unable to make a purchase if their bids are too low. In the souk, shortprice generators will be pleased.

The spot price would be driven to a competitive level by the power souk's souk dynamics. To estimate the market clearing price of trading days, the power exchange (PX) takes supply and demand bids. The MCP is established based on supply and demand bid curves, and all transactions take place there (Souk clearing price).MCP is the aggregate supply and demand graphs' souk equilibrium balancing price. PX's main goal is to create a demand requirement plan which satisfies consistency criteria while also maximizing societal welfare. In this sense, social welfare refers to the total of the consumer and supplier surpluses (Fig.3).

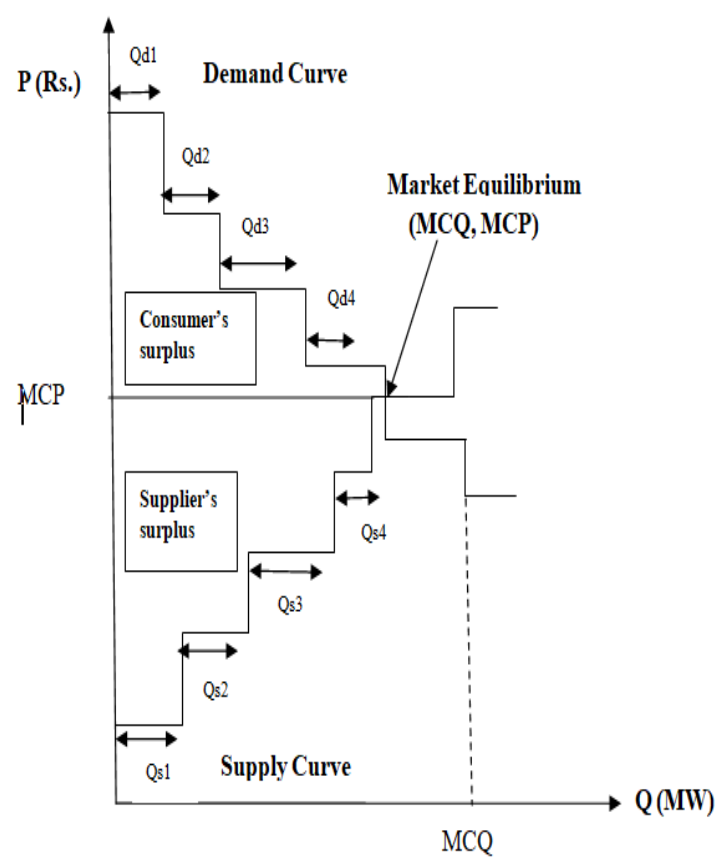

Fig. 3 Souk Equilibrium point and social welfare 


\subsection{Need of Building Model}

The monopoly in the generating sector is eliminated after the power market is deregulated. Any producer (supply) or major consumer (buyer) can now sell or buy electricity from any location. Energy exchanges can be found around the country, providing a forum for such transactions between suppliers and purchasers. In the global power market, there are primarily four types of bidding models. Each one's classification is detailed further below.

\subsubsection{Bidding in a one Part}

In first kind of auction, producers bid on behalf of different cost every hour, and cost fluctuates. Consequently, producers must reflect related expenses \&limitations while developing the proposal. This type of structure doesn't ensure that the entire cost is collected, therefore it is not feasible.

1.2.2 Bidding in several parts

A multipart bid is another name for a complicated bid Ramps, start-up and shut-down expenses, no-load operation, and energy are all charged individually. It's a good bid since it shows the real cost structure as well as the generators' technical parameter limitations (suppliers).In the market clearing process, the winning bid is optimised using an optimization technique. It causes the market operator to become the decision-making body for unit commitment choices, indicating that the market operator is the decision-making body. All bids must include all required information, and the market operator takes the most informed choices.

\subsubsection{Iterative Bidding}

It is the third step in the bidding process. In this kind of bidding, both the generator (supply) and the big user are permissible to modify/ adjust the offers as per specific regulations. This technique may require a considerable amount of computation, making it unfeasible. Because there is considerable debate over whether a single offer is adequate for a market to operate effectively, a novel method called as asynchronous type bid has been suggested. Generators (suppliers) can modify or adjust their offer once again after receiving generation stages of the initial round of MCP.

\subsubsection{Bidding on the Demand Side}

Demand side bidding may be used by large users to react to energy costs. Only producing units could determine the price of energy before; however, demand side bidding has been brought into the market, resulting in the maximization of societal welfare. Because the market that utilised a least cost strategy with producer side bid not exists, this method should now be used for bid clearing, which is unjust to sellers. In this approach to maximize social welfare demand side bidding was formerly prohibited; instead, a minimum price approach was used, in which large customers (buyers) remained passive and their profits were protected by law. Until now, most strategic bidding research has focused on the supply side of the equation, but many energy markets are adopting this strategy owing to its favourable effect on social welfare and profit.

\subsection{INDIA'S Bidding Scenario}

Energy trading was introduced in India by 2008. A souk was required in our country in which big buyers and sellers can gather and purchase or sold electricity at frank souk rates. The Electrical Statute of 2003 is the driving force behind the creation of such a souk place in India. The Power Act of 2003 signaled the start of an era of unprecedented innovation in the country's electricity markets. Positive regulatory measures to foster a competitive souk are also ongoing, bolstered by souk operators' efforts to offer innovative items and outcomes that advantage customer, producers, \& the energy industry. The unscheduled interchange (UI) souk (with unexpected pricing) and over the counter (OTC) trading methods were utilized to buy short-term electricity in India prior to the creation of power exchanges (which typically have high transaction costs).

Consumers previously wanted a platform that enabled them to create standard contracts, control counterparty risks, and provide stable, acceptable future power price indications. This task can only be done using over-the-counter products. India's energy trades now trade $30 \%$ of all electricity in the shortterm souk, making them a critical component in the demand-supply chain. The most significant energy trading platform in India is the Indian Energy Exchange (IEX).At initially; it just employed a few people. The number of players on the souk, on the other hand, has raised to 6238 , with 29 states and five union territories (UTs).

\section{LITERATURE REVIEW}

This paper [1] examined the best bidding processes in the Electricity Souk in detail. In [2, 3] David proposed a DP-based solution to the strategic bidding issue. In a pool-type electricity souk in England and Wales, Zhang et al. [4] suggested a similar method. A great deal of study is done on game theory based in competition-based energy souks. In an uncooperative game model method [5, 6], the bid approach issue is addressed by utilizing Nash equilibrium.

The GA was developed [7] to combine two separate bid algorithms to produce bid approach for a DAM. The spinning reserve souk, in combination with the energy souk, was given the same treatment in $[8$,$] .$ Uredo et al. planned a method for present block bids in consecutive power and auxiliary services souk places in [9], to evaluate demand uncertainty and competitor bidding behavior. Authors in [10] Used a stochastic programming method to generate linear bid curves for price-taking merchants with price-flexible customer loads in the Nord-pool souk. Opponents' bidding behavior may be depicted as a discrete PDF [11] or a continuous PDF [12] for a traders bid choice-making issues. Authors in [13] Discusses the 
effect of mutation parameter selection on bidding techniques in GA.

When risk limitations were taken into consideration, bid for one-sided and two-sided are simulated and resolved utilizing GA. The optimum bid approach issue is solved using PSO by $[15,16]$. Multi-stage programming and the swarm-based approach were recently utilized in the power souks to simulate modest strategic bidding [17].

Table 1 Characteristics of Models

\begin{tabular}{|c|c|}
\hline Models & Characteristics \\
\hline \multirow{5}{*}{$\begin{array}{l}\text { Single GenCo } \\
\text { Optimization }\end{array}$} & $\begin{array}{l}\text { Creating optimization models to characterize the entities in the electrical market to identify } \\
\text { the best solution. }\end{array}$ \\
\hline & Mathematical foundation that is well-established and sturdy. \\
\hline & $\begin{array}{l}\text { Generally concentrating on one unique person in the system while reducing the rest of the } \\
\text { system to a collection of exogenous variables. }\end{array}$ \\
\hline & Usually, no parts of players' intelligent behaviors are modified. \\
\hline & $\begin{array}{l}\text { It's difficult to model complicated, uncertain and dynamic systems, or to extract the best } \\
\text { bidding strategy for GenCos in deregulated power markets analytically. }\end{array}$ \\
\hline \multirow{6}{*}{ Game Theory } & $\begin{array}{l}\text { Modeling the electrical market as a game and quantitatively capturing the participants' } \\
\text { behavior in a game where one players' success in making decisions is influenced by the } \\
\text { decisions of others. }\end{array}$ \\
\hline & $\begin{array}{l}\text { A collection of game players' a set of bidding strategies, and a specification of payoffs for } \\
\text { each feasible combination of bidding strategies are all typically mathematically well-defined. }\end{array}$ \\
\hline & $\begin{array}{l}\text { Examining the electrical market's economic equilibrium by concentrating on the interactions } \\
\text { of the players. }\end{array}$ \\
\hline & $\begin{array}{l}\text { Capable of providing a justification and explanation for how strategic bidding behaviors } \\
\text { effect the GenCos market strength and earnings. }\end{array}$ \\
\hline & Everyone is believed to be reasonable, which isn't always the case. \\
\hline & $\begin{array}{l}\text { Multiple equilibriums are a bothersome problem that arises frequently when solving the } \\
\text { model. }\end{array}$ \\
\hline \multirow{6}{*}{ Agents-based } & Agents typically have imprecise local information and visibility, which they simply require. \\
\hline & $\begin{array}{l}\text { Although random components frequently exist among variable agents or in the system, no } \\
\text { centralized control or planning is necessary }\end{array}$ \\
\hline & $\begin{array}{l}\text { When compared to analytical methodologies, it is more versatile, robust, and simple to } \\
\text { execute. }\end{array}$ \\
\hline & $\begin{array}{l}\text { Capable of recording the finer nuances of agent's activity. This aids in determining the links } \\
\text { between individual decisions and system behavior }\end{array}$ \\
\hline & Capable of modeling the dynamics of non-equilibrium systems as well. \\
\hline & The mathematical foundation is still in its early stages. \\
\hline
\end{tabular}

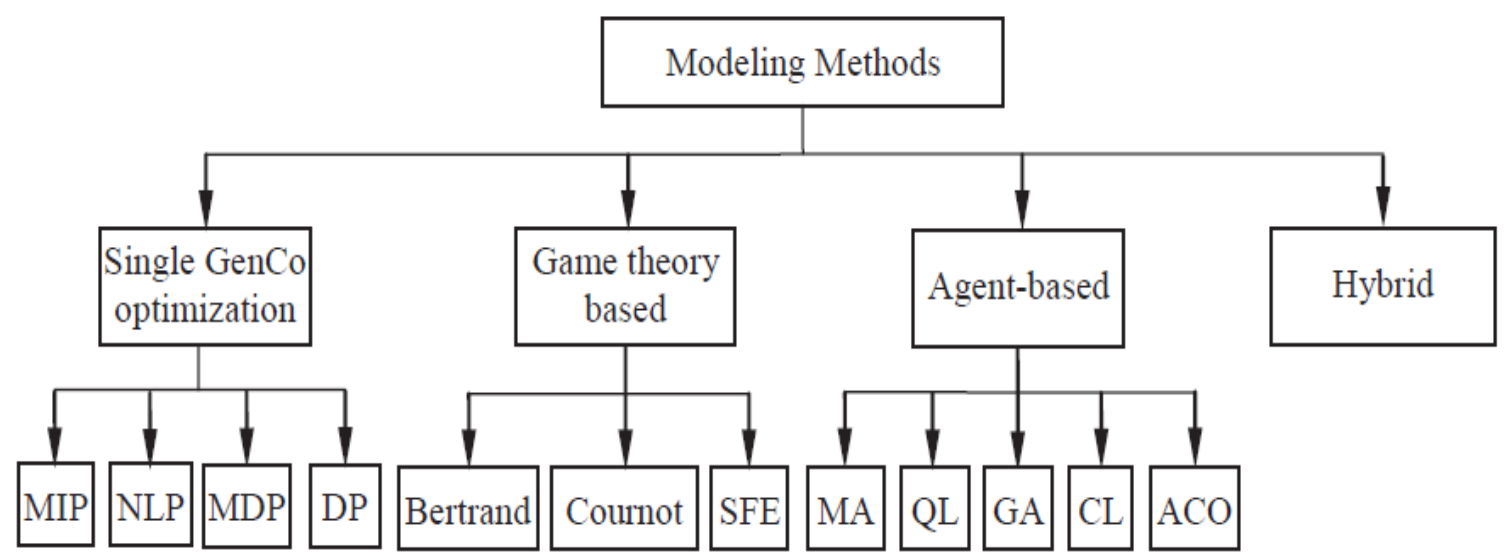

Fig. 4 Modeling literature for bidding strategy analysis in the electricity spot souk

\section{ELECTRICITY BIDDING IN SPOT SOUKS: MODELING TECHNIQUES}

Fig 4 depicts the four types of modeling literature for bidding strategy analysis in the electricity spot souk: for the participants interactions with each other, bidding techniques are studied using various models. Agent-based models have been used to simulate optimum bidding strategies and to imitate human behavior [30]. The three modeling methods are shown in Table 1 with their fundamental features. Recent proposals 
have also included hybrid and non-traditional methods

\section{SOLUTION TECHNIQUES}

Focus on the numerous modelling methods utilized to resolve the issue of optimum bid approach, which is talked in several literatures, based on different souk models and pricing comprised in a bid. Based on their problem formulation, individually collection of models can be broken down to smaller collection and techniques. Some of the modelling techniques used in optimization models include MIP, NLP, DP, and MDP. Other techniques may also be broken down into small groups. This method simplifies the profit maximization issue for a single player and managing the behaviour of another participant.

Saleh et al. [24] devised a Lagrange easing technique for a small GENCO's optimum bidding strategy, which took bilateral contract and unit commitment into consideration. Authors of [25] describes a method for detecting souk clearance prices that uses one and two-side auction processes. To address the optimization issue, the linear programming software is employed. $\mathrm{Yu} \mathrm{Z}$ et al. [26] introduced a MINLP method for calculating real power, souk clearing prices, and auxiliary services. Authors in [27] solves the multi-stage stochastic MILP issue, and a study of wind power business in Kansas is done as a LP model, resulting in greater gain and reduced hazard.

Bonchuay and his colleagues [28] proposed an optimum bidding method for price takers that included risk management. It is utilized to solve the best bidding strategy issue in multi-hourly trading in a uniform pricing spot souk, and the results are compared to those of other particle swarm optimization methods. To model rivals' bidding behaviour in a competitive environment, the Monte Carlo (MC) approach is used. Equilibrium models are a term used to describe game theory models. The profit maximization issue for price takers is eased in this method by taking into consideration the strategic behaviour of other players' interactions.

Game Theory is a model of how people interact with each other. Game theory can be classified into two types: cooperative and non-cooperative. Price takers in this model followed certain souk norms and interacted intelligently and dynamically with one another, enabling the creation of models that better mimic competitive power souks. The system's real performance, on the other hand, is restricted by its technical connections.

PSO's search method is based on the idea of a group's members learning together in both cognitive and social ways. For a linear SFE model utilizing PSO with a two-level optimization problem presented in [29], profit maximization with network constraints is obtained. The parameterization methods used to create the optimum supply function are investigated considering the simulation results. Various academicians have proposed non-traditional and hybrid methods for strategic bidding problems in addition to the three modelling approaches listed above. An optimization technique was used to quote rates in the PJM souk, and the outcomes were found to be reasonable and accurate when compared to previous research. Soleimani et al. are a group of researchers that came up with a novel way to solve [30].



Fig. 5 Flow Chart of Optimal bidding strategy

\section{CONCLUSION}

This review gives an outline of the many projects that have been undertaken in the field of souk power. This research also included a systematic review of recent papers, as well as an examination of bid approach in the deregulated power market. Many souks design and bid behaviour souks are investigated, and numerous models such as equilibrium model, agentbased models are accessible in the literature for investment bid approaches.

\section{REFERENCES}

[1] David, A.K., and Wen, F. 'Strategic bidding in competitive electricity souks: a literature survey'. IEEE PES Summer Meeting, 2000, vol. 4, pp. 2168-2173.

[2] David, A.K.: 'Competitive bidding in electricity supply', IEE Proc., Gener. Trans. Dist., 1993, 140, (5), pp. 421-426.

[3] Gross, G., and Finlay, D.J.: 'Optimal bidding strategies in 
competitive electricity souks. Proc. 12th Power System Computation Conf., August 1996, pp. 815-823.

[4] Zhang, D., Wang, Y., and Luh, P.B.: 'Optimization based bidding strategies in deregulated souk'. Proc. IEEE PES Power Industry Computer Applications Conf., 1999, pp. 63 68.

[5] Ferrero, R.W., Ramesh, V.C., and Shahidehpour, S.M.: Transaction analysis in deregulated power system using game theory', IEEE Trans. Power Syst., 1997, 12, (3), pp. 1340-1347.

[6] Torre, S.D., Conejo, A.J., and Contreras, J.: 'Finding multiperiod Nash equilibrium in pool-based electricity souks' IEEE Trans. Power Syst., 2004, 19, (1), pp. 643-651.

[7] David, A.K., and Wen, F.: 'Strategic bidding for electricity supply in a day-ahead energy souk', Electr. Power Syst. Res., 2001, 59, pp. 197-206.

[8] David, A.K., and Wen, F.: 'Optimally co-ordinated bidding strategies in energy and ancillary service souks', IEE Proc., Gener. Tran. .Dis. 2002, 149, (3), pp. 331-338.

[9] Ugedo, A., Lobato, E., Franco, A., Rouco, L., FernándezCaro, J., and Chofr, J.: 'Strategic bidding in sequential electricity souks', IEE Proc. Gener. Tran. Dis., 2006, 153 (4), pp. 431-442.

[10] Fleten, S.-E., and Pettersen, E.: 'Constructing bidding curves for a price-taking retailer in the Norwegian electricity souk', IEEE Trans. Power Syst., 2005, 20, (2), pp. 701-708.

[11] Song, H.L., Liu, C.C., and Lawree, J.: 'Decision making of an electricity suppliers bid in a spot souk'. Proc. IEEE Power Engineering Society Summer Meeting, 1999, vol. 1, pp. 692 696.

[12] David, A.K., and Wen, F.S.: 'Optimal bidding strategies for competitive generators and large consumers', Elect. .Power Syst, 2001, 23, (1), pp. 37-43.

[13] Gan K. S., Anthony P. and Teo J. Mutation rate in the evolution of bidding strategies, The 3rd International Symposium on Information Technology 2008.

[14] A.k.Jain. and S.C.srivastava. Strategic Bidding and risk Assessment Using Genetic Algorithm in Electricity Souks International Journal of Emerging Electric Power Systems, 2009, Vol.10

[15] P.Bajpai, S.K.Punna and S.N.Singh. "Swarm intelligencebased strategic bidding in competitive electricity souks". IET Gener. Trans. Distr. 2008, (2), pp.175-184.

[16] K. Kanakasabhapathy, K. Shanti Swarup." Evolutionary Tristate PSO for strategic Bidding of Pumped-Storage Hydroelectricplant". IEEE Trans. on Syst. Man, and Cybernetics. Vol. 40, No. 4, July 2010.

[17] Guangquan Zhang, Guoli Zhang, Ya Gao, and JieLu.:"Competitive Strategic Bidding Optimization in Electricity Souk using Bi-level Programming and Swarm Technique.", IEEE Transactions on Industrial Electronics, Vol. 58, No. 6, June 2011.

[18] Srivastava Anurag K, Kamalasadan Sukumar, Patel Daxa, Sankar Sandhya, Al-Olimat Khalid S. Electricity souks: an overview and comparative study. Int Energy Sec Manage 2011; 5(2):169-200.

[19] Yuan-Kang, Wu. "Comparison of pricing schemes of several deregulated electricity souks in the world". In: IEEE/PES transmission and distribution conference and exhibition: Asia and Pacific Dalian, China; 2005.
[20] Lamoureux MA. Evolution of electric utility restructuring in the UK.IEEE Power Eng Rev 2001; 21(6):3-5.

[21] Outhred H. Managing availability, quality and security in a restructured electricity industry with reference to the Australian national electricity souk. In: Proceedings of the 39th annual Hawaii international conference on system sciences, HICSS '06; 2006.

[22] Ni Yixin, Zhong Jin, Liu Haoming. Deregulation of power systems in Asia: special consideration in developing countries. In: IEEE power engineering society general meeting, vol. 3; 2005. p. 2876-81.

[23] Shukla Umesh Kumar, Thampy Ashok. Analysis of competition and souk power in the wholesale electricity souk in India. Energy Policy2011; 39:2699-710.

[24] Saleh A, Tsuji T, Oyama T, "Optimal bidding strategies for a small generation company in a day-ahead electricity souk with bilateral contracts taken into account". Am J Eng Appl Sci 2009; 2(1):176-83.

[25] Gutierrez G, Quinonez J, Sheble GB, "Souk clearing price discovery in a single and double-side auction souk mechanisms: linear programming solution". IEEE Power Technol Russia 2005:1-5.

[26] Yu Z, Nderitu DG, Sparrow FT, Gotham DJ, "Optimal and reliable dispatch of supply and demand bids for competitive electricity souks". In: IEEE power engineering society summer meeting, vol. 4; 2000. P.2138-43.

[27] Morales JM, Conejo AJ, Perez-Ruiz J., "Short-Term trading for a wind power producer". IEEE Transactions on Power Systems 2010; 25(1)

[28] Boonchuay C, Ongsakul W. "Optimal risky bidding strategy for a generating company by self organizing hierarchical PSO”. Energy Conversion and Management 2011; 52(2).

[29] KianA, Cruz JB, Thomas RJ, "Bidding strategies in oligopolistic dynamic electricity double-sided auctions". IEEE Transactions on Power Systems 2005; 20(1):50-8.

[30] Christopher J. Day, Benjamin F. Hobbs Pang JS "Oligopolistic competition in power networks: a conjectured supply function approach". IEEE Trans Power Syst 2002; 17(3):597-607.

[31] Weglarz M, Wylomanska A. "Optimal bidding strategies on the power souk based on the stochastic models". In: International symposium on modern electric power systems, Wroclaw, Poland; 2010. p. 1-6.

[32] Li T, Shahidehpour M. "Strategic bidding of transmission constrained GENCOs with incomplete information". IEEE Transactions on Power Systems 2005; 20(1):437-447

[33] Richter C, Sheble G. Genetic algorithm evaluation of utility bidding strategies for the competitive souk place. IEEE Trans Power Syst 1998; 13:256-61.

[34] Azadeh A, Ghaderi SF, Pourvalikhan Nokhandan B, Sheikhalishahi M.A new genetic algorithm approach for optimizing bidding strategy viewpoint of profit maximization of a generation company. Expert Syst Appl 2012; 39:156574 .

[35] Mathur S, Arya A, Dubey M. "Optimal bidding strategy for price takers and customers in a competitive electricity market" Cogent Engineering (2017), 4: 1358545.

[36] Bajpai P, Punna SK, Singh SN. "Swarm intelligence-based strategicbidding in competitive electricity souks". IET Gener Transm Distrib2008; 2(2):175- 